\title{
Estrogenic Potency of a Bisphenol A Metabolite on Vitellogenin Synthesis in Medaka, Oryzias latipes
}

\author{
Masaki Nagae, ${ }^{*, a}$ Ken'ichirou Shiroyama, ${ }^{a}$ Mihoka Inoue,${ }^{c}$ Akihiko Hara, ${ }^{c}$ Yuji Takao, ${ }^{a}$ \\ Shinya Kohra, ${ }^{a}$ Yasuhiro Ishibashi, ${ }^{b}$ Nobuaki Tominaga, ${ }^{d}$ Shin'ichi Yoshihara, ${ }^{e}$ \\ and Koji Arizono
}

${ }^{a}$ Faculty of Environmental Studies and ${ }^{b}$ Environmental Protection Center, Nagasaki University, 1-14 Bunkyo-machi, Nagasaki 8528521, Japan, 'Division of Marine Bioscience, Graduate School of Fisheries Science, 3-1-1 Minatochou, Hakodate 041-0802, Japan, ${ }^{d}$ Department of Chemical and Biological Engineering, Ariake National College of Technology, 150 Higashihagino-machi, Omuta 8368585, Japan, ${ }^{e}$ Department of Xenobiotic Metabolism and Molecular Toxicology, Graduate School of Biomedical Science, Hiroshima University, 1-2-3 Kasumi, Hiroshima 734-8851, Japan, and ${ }^{f} F$ aculty of Environmental and Symbiotic Sciences, Prefectural University of Kumamoto, Tsukide 3-1-100, Kumamoto 862-8502, Japan

(Received September 21, 2004; Accepted October 4, 2004; Published online October 7, 2004)

We investigated the estrogenic activity of a bisphenol A (BPA) metabolite (4-methyl-2,4-bis( $p$ hydroxyphenyl)-pent-1-ene; MBP) in male medaka (Oryzias latipes) using vitellogenin (Vg, Vg1 and Vg2) as a biomarker. Male d-rR medaka were exposed to various concentrations of estradiol-17 $\beta\left(E_{2}\right), M B P$ and BPA for 3 days, and then the serum Vg concentration was measured using specific chemiluminescent immunoassays. The estimated relative estrogenic activities of MBP and BPA compared with $\mathrm{E}_{2}(\mathbf{1 0 0 \%})$ were 1.3$1.4 \%$ and $0.00010-0.00023 \%$, respectively. These findings indicated that MBP has about $10^{4}$-fold higher estrogenic potency than the parent BPA and about 1/50 that of $E_{2}$ for Vg synthesis in medaka. This is the first study to show that MBP can act as a highly potent estrogen agonist in living organisms.

Key words — bisphenol A metabolite, estrogenic activity, vitellogenin, 4-methyl-2,4-bis( $p$-hydroxyphenyl)pent-1-ene, medaka

\section{INTRODUCTION}

Bisphenol A (2,2-bis(4-hydroxyphenyl)propane; $\mathrm{BPA}$ ) is a raw material that is used in the worldwide production of polycarbonate and epoxy resins. Large production volumes and consumption of BPA have led to its being detected in human biological flu-

*To whom correspondence should be addressed: Faculty of Environmental Studies, Nagasaki University, 1-14 Bunkyomachi, Nagasaki 852-8521, Japan. Tel.: +81-95-819-2755; Fax: +81-95-819-2757; E-mail: nagae@net.nagasaki-u.ac.jp ids ${ }^{1,2)}$ and in aquatic environments. ${ }^{3-5)}$ The notion that BPA possesses weak estrogenic activity and disrupts the endocrine system is widely accepted. Yoshihara et al. recently found that 4-methyl-2,4-bis( $p$ hydroxyphenyl)-pent-1-ene (MBP), a BPA metabolite in the rat liver S9 fraction, has several hundredto several thousand-fold higher estrogenic potency than BPA itself. ${ }^{6,7)}$ If BPA is converted to MBP in the environment and if it negatively affects the endocrine system of living organisms, the biological risk of BPA should be reconsidered. However, only one report has described the estrogenic activity of BPA in vitro, and the estrogenic impact of MBP has not been investigated in vivo. Vitellogenin $(\mathrm{Vg})$, a precursor of yolk protein in oviparous animals, is a good biomarker of estrogenomimetic activity because it is synthesized in the liver and is powerfully regulated by estrogen. Here, we evaluated the estrogenic potency of MBP in medaka in vivo using Vg as a biomarker.

\section{MATERIALS AND METHODS}

Fish and MBP Exposure —_ Adult male medaka $\left(\mathrm{d}-\mathrm{rR}\right.$ strain ${ }^{8)}$ ) maintained in 60-1 glass aquaria under a 14-hr light : 10 -hr dark cycle at $25 \pm 1^{\circ} \mathrm{C}$ were fed daily with a commercial mix of freeze dried, dayold brine shrimp (Artemia Gold; Nagasaki Rikagaku Co., Nagasaki, Japan).

Groups of 3 male fish were transferred to 2-1 glass beakers containing dechlorinated tap water. Steroid and chemicals were dissolved in ethanol and added to the water at the following nominal concen- 

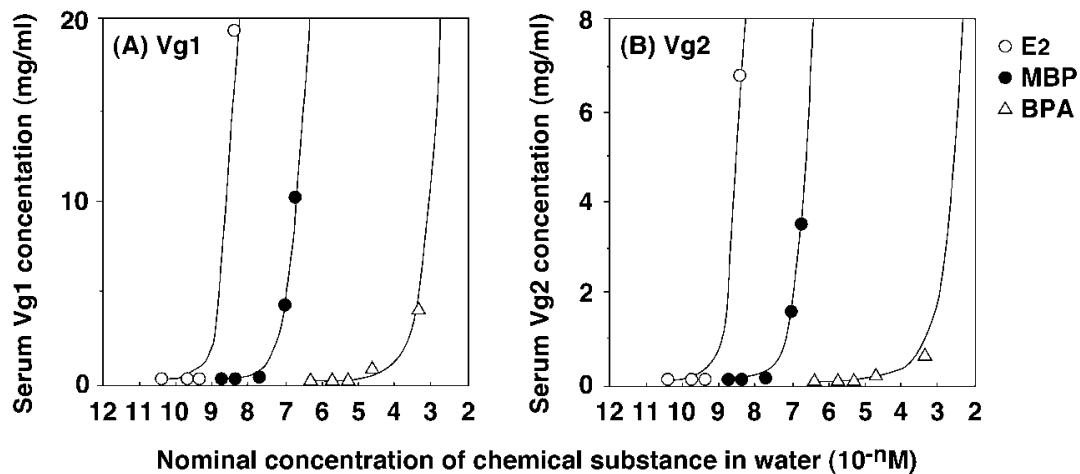

Fig. 1. Serum Vg1 (A) and Vg2 (B) Concentrations in Male Medaka Exposed to $\mathrm{E}_{2}$ (Open Circles), MBP (Closed Circles) and BPA (Open Rectangles) for 3 days

Table 1. Estrogenic Potency of MBP on Vg Synthesis

\begin{tabular}{lcc}
\hline \hline $\begin{array}{l}\text { Hormones or } \\
\text { chemicals }\end{array}$ & $\begin{array}{c}\text { Effective concentration required to } \\
\text { induce } 10 \mathrm{mg} / \mathrm{ml} \mathrm{Vg} 1 \text { in serum }\end{array}$ & $\begin{array}{c}\text { Effective concentration required to } \\
\text { induce } 5 \mathrm{mg} / \mathrm{ml} \mathrm{Vg} 2 \text { in serum }\end{array}$ \\
\hline $\mathrm{E}_{2}$ & $2.5 \times 10^{-9} \mathrm{M}(100)$ & $3.3 \times 10^{-9} \mathrm{M}(100)$ \\
$\mathrm{MBP}$ & $1.8 \times 10^{-7} \mathrm{M} \quad(1.4)$ & $2.6 \times 10^{-7} \mathrm{M} \quad(1.3)$ \\
$\mathrm{BPA}$ & $1.1 \times 10^{-3} \mathrm{M} \quad(0.00023)$ & $3.6 \times 10^{-3} \mathrm{M} \quad(0.00010)$ \\
\hline
\end{tabular}

Regression formula of test chemical concentration-Vg response curve calculated from data described in Fig. 1. From these results, effective concentrations of test chemicals required to induce $10 \mathrm{mg} / \mathrm{ml} \mathrm{Vg} 1$ and $5 \mathrm{mg} / \mathrm{ml} \mathrm{Vg} 2$ in serum were calculated. Values in parenthesis indicate percentage of relative estrogenic activity compared with $\mathrm{E}_{2}$.

trations: $17 \beta$-estradiol $\left(\mathrm{E}_{2} ;\right.$ Sigma-Aldrich, St. Louis, MO, U.S.A.), 0.01, 0.05, 0.1, 0.5 and $1 \mathrm{ppb}$; MBP (synthesized and purified MBP as described by Takao et al..$^{9)}$ ), 1, 5, 25 and $50 \mathrm{ppb}$; BPA (Tokyo Chemical Industry Co., Ltd., Tokyo, Japan), 100, 500, 1000, 5000 and $10000 \mathrm{ppb}$. Controls contained appropriate volumes of vehicle solvent $(0.1 \mathrm{ml} / \mathrm{l})$. The solutions were replaced every day for 3 days and the fish were not fed during exposure to chemicals. The caudal peduncle was severed and blood from the groups was collected into micro-capillary tubes (Microcaps; Drummond Scientific Co., PA, U.S.A.). Serum was separated by centrifugation at $10000 \times g$ for $5 \mathrm{~min}$ and stored at $-30^{\circ} \mathrm{C}$.

\section{Measurement of Serum Vg Concentration}

Serum concentrations of $\mathrm{Vg} 1$ and $\mathrm{Vg}$ 2, were measured using specific chemiluminescent immunoassays $^{10)}$ as follows. Ninety-six well polystyrene luminescence immunoassay plates (LIA plates; Greiner, Frickenhausen, Germany) were coated with either anti-Vg1 or anti $\mathrm{Vg} 2 \mathrm{IgG}$, and blocked with $1 \%$ BSA and $0.1 \%$ bovine $\gamma$ globulin to prevent nonspecific binding. Serum samples or $\mathrm{Vg}$ standard were placed into the wells and incubated for $3 \mathrm{hr}$ at $15^{\circ} \mathrm{C}$ (1st reaction). The plates were washed and acridinium-labeled $F(a b ') 2$ of anti- $\mathrm{Vg}$ IgG was added (2nd reaction) for $1 \mathrm{hr}$ at $15^{\circ} \mathrm{C}$. The chemiluminescent reaction (Reagents 1 and 2; CHIRON, Emeryville, CA, U.S.A.) and luminescence detection were controlled using a Luminescencer-JNR (ATTO, Tokyo, Japan). All assays were performed in duplicate.

\section{RESULTS AND DISCUSSION}

Figure 1 describes the serum $\mathrm{Vg} 1$ and $\mathrm{Vg} 2$ concentrations of male medaka exposed to various doses of $E_{2}, M B P$ and BPA. All chemicals at the tested concentrations dose-dependently increased the serum $\mathrm{Vg}$ concentration and regression curves of the 3 exposure groups were almost parallel. The LOEC (Lowest Observed Effect Concentration) values for $\mathrm{E}_{2}, \mathrm{MBP}$ and BPA on the synthesis of both Vgs were $3.7 \times 10^{-9}, 9.2 \times 10^{-8}$ and $2.2 \times 10^{-5} \mathrm{M}$, respectively. The estimated relative estrogenic activities of MBP and BPA (percentage compared with $\mathrm{E}_{2}$ ) calculated from the regression curves were 1.3-1.4 and $0.00010-0.00023 \%$, respectively (Table 1 ). These findings showed that MBP has extremely high estrogenic activity (about $10^{4}$-fold that of parent BPA, and about $1 / 50$ of that of $E_{2}$ ) on $\mathrm{Vg}$ synthesis in male 
medaka. The present findings closely correlated with in vitro evaluations of estrogenic MBP activity. ${ }^{7)}$

A recent report has indicated that not only sunlight but also fluorescent light can photolyze MBP. ${ }^{8)}$ Here, we exposed male medaka to chemicals under white fluorescent light ( $14 \mathrm{hr} /$ day $)$. Therefore, the estrogenic potency of MBP might be increased by repeating the present study under darkness. Yoshihara et al. considered that MBP might become metabolically activated under conditions of poor glucuronidation capacity as in rat and human fetuses, but not under normal circumstances. ${ }^{7)}$ A similar situation might be extant during the early development of lower vertebrates. Aquatic animals, fish fry or premetamorphous amphibians, can easily absorb BPA from water. The present study revealed an extremely potent estrogenic effect of MBP in teleosts in vivo. Therefore, MBP concentrations in these animals should be investigated during early development to enhance understanding of the estrogenic effect of BPA.

\section{REFERENCES}

1) Sajiki, J., Takahashi, K. and Yonekubo, J. (1999) Sensitive method for the determination of bisphenolA in serum using two systems of high-performance liquid chromatography. J. Chromatogr. B, 736, 255261.

2) Ikezuki, Y., Tsutsumi, O., Takai, Y., Kamei, Y. and Taketani, Y. (2002) Determination of bisphenol A concentrations in human biological fluids reveals significant early prenatal exposure. Hum. Reprod., 17, 2839-2841.

3) Bolz, U., Hagenmaier, H. and Korner, W. (2001)
Phenolic xenoestrogens in surface water, sediments, and sewage sludge from Baden-Wurttemberg, southwest Germany. Environ. Pollut., 115, 291-301.

4) Fromme, H., Kuchler, T., Otto, T., Pilz, K., Muller, J. and Wenzel, A. (2002) Occurrence of phthalates and bisphenol $\mathrm{A}$ and $\mathrm{F}$ in the environment. Water Res., 36, 1429-1438.

5) Kuch, H. M. and Ballschmiter, K. (2001) Determination of endocrine-disrupting phenolic compounds and estrogens in surface and drinking water by HRGC-(NCI)-MS in the picogram per liter range. Environ. Sci. Technol., 35, 3201-3206.

6) Yoshihara, S., Makishima, M., Suzuki, N. and Ohta, S. (2001) Metabolic activation of bisphenol A by rat liver S9 fraction. Toxicol. Sci., 62, 221-227.

7) Yoshihara, S., Mizutare, Y., Makishima, M., Suzuki, N., Fujimoto, N., Igarashi, K. and Ohta, S. (2004) Potent estrogenic metabolites of bisphenol A and bisphenol B formed by rat liver S9 fraction: their structures and estrogenic potency. Toxicol. Sci., 78, 50-59.

8) Yamamoto, T. (1953) Artificially induced sexreversal in genotypic males of the medaka (Oryzias latipes). J. Exp. Zool., 123, 571-594.

9) Takao, Y., Shimazu, M., Kohra, S., Nagae, M., Ishibashi, Y., Tominaga, N., Ishibashi, H., Yoshihara, S. and Arizono, K. (2004) Photodecomposition and bioconcentration of a bisphenol A metabolite in medaka, Oryzias latipes. J. Health Sci., 50, 576580 .

10) Inoue, M., Fujiwara, Y., Fukada, H., Shimizu, M., Fujino, H. and Hara, A. (2003) Changes of two types vitellogenins in serum of Medaka (Oryzias latipes) exposed to estrogen. In Abstracts of The 6th Annual Meeting of Japan Society of Endocrine Disrupters Research, Sendai, Japan, p. 219. 